\title{
Mental hygiene of interpersonal relations of student-managers in a megapolis
}

\author{
Nikolay Dedov ${ }^{1 *}$, Olga Komissarova ${ }^{2}$, Irina Kokhova $^{1}$, Oleg Petrunya ${ }^{3}$, and Tatyana \\ Gerasimenko ${ }^{4}$ \\ ${ }^{1}$ Financial University under the Government of the Russian Federation, Moscow, Russia \\ ${ }^{2}$ Moscow University named after S.Yu. Witte, Moscow, Russia \\ ${ }^{3}$ Moscow Aviation Institute (National Research University), Moscow, Russia \\ ${ }^{4}$ Russian University of Economics named after G.V. Plekhanov, Moscow, Russia
}

\begin{abstract}
The article presents a psychological analysis of the behavior features and interpersonal relations of students-managers in a metropolis. The relevance of the present work is determined by the fact that for young people, higher education is associated with a change in their social status when they move from direct dependence on their parents to independent actions and active life in a big city. The specifics of the urban space of a metropolis have a strong influence on their mental state and understanding of the world around them. The popularity of the manager's profession among young people entering universities has also contributed to the relevance of the study. Young people set themselves the goal of "learning to manage and lead." The conditions of the big city impose special requirements on future managers, focusing them on the implementation of adaptive psychological functions. The manager's ability to conform to social attitudes, to create a pleasant impression for others becomes for him a professionally important quality. As a result, students face a paradoxical situation involving a system of "double standards". In this regard, they encounter difficulties in social adaptation and the formation of stable interpersonal relationships. To solve this problem, an empirical study was conducted, which allowed determining the values of the main strategies of interpersonal relations based on a comparative analysis of the basic ideas of first-year students. Empirical data were obtained based on the psychological method by L.N. Sobchik "Diagnostics of interpersonal relations" (DIR). The results obtained make it possible to carry out preventive psychohygienic activities with students to form their social adaptability and maintain mental health.
\end{abstract}

Keywords: personality, successful manager, interpersonal relations, development.

*Corresponding author: vedun60@yandex.ru 


\section{Introduction}

The specificity of life in a big city, a metropolis, is that the actions and behaviors of its inhabitants imply a high intensity of contacts among them. At the same time, such close communication also implies the presence of social isolation among the participants, and loneliness. This results in a kind of exhaustion of relations, when a high level of sociability, on the one hand, coexists with social autism. Metropolis is a huge urbanized area, characterized by a high population density, information overload, the presence of stress and extremes $[1,2]$. The individual, from the moment of birth, feels like a small "cog" in this huge mechanism.

The admission of a young person to a higher educational institution dramatically changes his behavior, thinking peculiarities. Besides, his realm of feelings and experiences is reconstructed [3]. He faces radical transformations both in his mental life and in the sphere of real contact with other people. While before, the relationships with the outside world were limited to close relatives, friends, and classmates, now a huge number of random people appear in his living space. As a result, first-year students often experience depressive moods, decreased mental activity, and maladaptive behavior [4]. Thus, studying at a university becomes a serious psychological test or even stress for them.

In contemporary socio-economic conditions, the most promising and attractive profession for applicants is considered to be the profession of the manager. From the standpoint of contemporary management, a manager is a person who manages processes, personnel, and production, with the aim of its effective organization and optimization [5]. Managing people involves the manager's knowledge of the leading rules and patterns that underlie interpersonal communications and business relationships.

Training of students at the university in the management specialty initially sets a strict requirement regarding their sociability, in-touch capabilities, and outgoingness. These are professionally important qualities for them. Almost the same requirements are necessary for young people when they live in a metropolis. Violations in this area lead to social maladaptation. In this regard, interpersonal relationships in the metropolis acquire social significance for young people and, therefore, they have to independently find the best ways for their adaptation both at the university and in the big city. That is why the development of preventive and psychogenic measures of adaptive behavior becomes an important element of the educational process.

\section{Methods}

Interpersonal relationships are a socio-psychological category that can be used to study the individual characteristics of the person, their social orientation, and the originality of their inner world [6]. Concerning someone or something, the subject reveals not only himself, his psychological qualities, but also determines his adaptive capabilities [7]. In the course of interaction with the outside world, an individual also identifies the main strategies for the most effective relationships, which are based on attitudes, and stereotypical assessments of people around them. Thus, he sets and predetermines his actions with social priorities, realizing, at the same time, their value. Due to such actions, the subject forms his own "Iconcept", which manifests itself in the form of a representation of himself. "The Self-image becomes for the individual his inner essence, which is formed in the course of selfobservation and self-knowledge" [8]. The most detailed definition of the "I-concept" is given by R. Burns, who defines it as "the totality of all the ideas of the individual about himself, which is conditioned by the corresponding assessment" [9]. Domestic scholars also pay attention to the multiplicity of "I-images" [10]. In their opinion, it develops in the course of 
self-actualization of the subject, due to a positive attitude towards oneself on the part of significant others [11].

The specificity of the present research is to analyze and study the psychological characteristics of participants (first-year students) living in Moscow city metropolis. Students acquire the specialty of the manager and, in this regard, give ratings to their "real me", "ideal me", and the image of a "successful manager". At that, the image of a "successful manager" is considered by the authors of the present article as an indicator of successful adaptative option of the students' socialization in a metropolis [3]. Its relationship with other profiles will allow developing a system of methodological recommendations for the prevention of socio-psychological problems in the field of interpersonal relations that arise in students specialized in the management and living in the metropolis.

The sample of testees consisted of first-year students of Moscow universities (120 people) studying in the management specialty. The age of young people ranged from 17 to 19 years.

\section{Methods}

To obtain the necessary results, the authors employed "Diagnostics of interpersonal relations (DIR)" method developed by Sobchik [12], which was a modified version of the T. Leary's interpersonal diagnostics method [13]. The diagnostic value of this technique is that it allows, on the one hand, analyzing students' ideas concerning the subjective images of "real me", "ideal me", and "successful manager", while, on the other hand, identifying the qualitative originality of interpersonal relationships of respondents, which determines their adaptive abilities in the metropolis [11].

The questionnaire was based on a psychological technique that included a set of 128 psychological qualities. To obtain significant differences, the statistical method of processing the results of the nonparametric Mann-Whitney U-test was used.

\section{Results}

The participants involved in the survey were offered standard forms of the DIR questionnaire. After the survey, individual scores were calculated for each participant based on the available keys. Thus, the qualitative and quantitative processing of the received answers of first-year students studying in the management specialty was carried out for each octant (scale) with the calculation of their average indicators. According to the results obtained, it became possible to talk about a certain type of interpersonal relationships of young people who were studying in a large metropolis like the city of Moscow. Averaged indicators for the octants of the DIR methodology have shown the specificity and originality of the distribution of firstyear students" ideas about themselves (("real me") and ("ideal me")), as well as their idea of a "successful manager". Results are presented in Table 1.

Table 1. Results of the survey.

\begin{tabular}{|c|c|c|c|}
\hline & $\begin{array}{c}\text { Successful } \\
\text { manager }\end{array}$ & Real me & Ideal me \\
\hline I & 11.8 & 8.7 & 10.3 \\
\hline II & 8.7 & 7.3 & 7.8 \\
\hline III & 6.7 & 7.0 & 7.7 \\
\hline IV & 2.4 & 7.6 & 2.8 \\
\hline V & 2.8 & 4.8 & 3.6 \\
\hline VI & 3.1 & 4.5 & 3.7 \\
\hline VII & 6.8 & 7.1 & 7.1 \\
\hline VIII & 5.6 & 6.3 & 8.7 \\
\hline
\end{tabular}


The next stage of the study was the statistical processing of the results obtained using the nonparametric Mann-Whitney $U$ test, which had indicated the existence of statistically significant differences between subjective perceptions in first-year students. Their education at universities in a big city like Moscow has impact on their perception of own image, as well as their status in society. Stable patterns were identified between the images of "real me" and "ideal me" in the fifth octant $(\mathrm{U}=53.5, \mathrm{P}=0.0001)$. Besides their significant correlation with the image of "successful manager" was noted in the first $(\mathrm{U}=98, \mathrm{P}=0.0001)$ and fourth $(\mathrm{U}=36, \mathrm{P}=0.0001)$ octants with "real me" of students, and in eighth $(\mathrm{U}=122.5, \mathrm{P}=0.002)$ octant with "ideal me".

The results obtained in the study and their statistical analysis allowed speaking about the existence of a significant difference between students" ideas about the "real me" and "ideal me" in the fourth octant corresponding to incredulous-skeptical determinant. According to the participants, critical attitude, suspicion, and distrust (7.6 points), characteristic of the real situation of their existence in the metropolis, should radically change ( 2.8 points) to realism in their views, actions, and judgments. In this regard, they should form adequate world views, where the emerging interpersonal relationships reflect the situation here and now, without any cognitive distortions and emotional biases.

Comparison of the selected images of "I" with the image of "successful manager" in the representation of first-year students (managers) had also shown significant statistical differences. These indicators showed a tendency to change of their perception of the image of a "successful manager". Here, the values of the first octant "imperious-pacesetting" increased to 11.8 points, i.e. the students believed that the future effective and socially adapted specialist should show high social activity, dominance, and self-confidence. The revealed significant differences in the fourth octant "distrustful-skeptical" confirmed the previous results of the comparison between "real me" and "ideal me" (decreasing to 2.5 points). This proved the fact that clear-eyed perception, criticism, and pragmatism, which were indicators of life in a big city, acquired an important indicator of adaptive behavior for students majoring in management. Young people's skepticism, uncertainty, and suspicion should, in their opinion, gradually transform into socially acceptable communications [14]. Thus, students should begin to accept future life without embellishment.

A decreasing trend of values in eighth octant "responsible-generous" of ideal self-image (8.8 points) to level (5.7 points) in the image of a "successful manager" revealed the specificity of the focus of interest of students majoring in the management. For them, one of the main tasks was the adaptation process which was due to the actualization of socially approved patterns of behavior adopted in the metropolis. Following the generally accepted norms of behavior, conventionality, sociability, cooperation, and altruism initially created prerequisites for successful social adaptation and inclusion in the rhythm of the big city. As a result, the desire to create a pleasant impression for others, and social desirability predetermined the formation of double standards in their mental activity [15].

\section{Conclusion}

Summarizing the results obtained, it can be noted that the purpose of the study has been largely achieved. Comparing the image of a "successful manager" with a conventional citizen with the real and ideal self-images by future managers indicates the formation of their adaptation strategy. In current socio-economic conditions, where the majority of interactions are built on flexibility in interpersonal contacts, the ability to understand the partner based on communication, to adapt to his individual characteristics, the styles of interpersonal relations chosen by students have positive impact on their mental health and well-being. Thus, the results obtained in the study indicate the relevance and significance of the problem of social adaptation of today's students in the context of the metropolis. This leads to the 
emergence of an urgent need to develop a set of psychological and social recommendations, conduct training, and psychogenic classes to make students aware of their personal qualities. First-year students, acquiring the necessary knowledge about future life in the big city, should subsequently initiate the appropriate psychological qualities of a successful professional, and a successful manager.

\section{References}

1. S.P. Paramonova, Yu.I. Suntsov, Yu.V. Denisov, Bulletin of the Perm National Research Polytechnic University. Socio-economic sciences, 1, 69-76 (2018). https://doi.org/10.15593/2224-9354/2018.1.6

2. O.E. Petrunya, A.A. Kozlyakov, Philosophy of Education, 1(37), 15-19 (2018).

3. V.V. Golubev, I.A. Umanskaya, Bulletin of Kostroma State University named after N.A. Nekrasov, 26(1), 118-123 (2020). https://doi.org/10.34216/2073-1426-2020-261-118-123

4. M.V. Polevaya, Ye.V. Kamneva, Adaptation of first-year students: psychological and educational aspect, in Actual problems of social and economic psychology: methodology, theory, practice. Collection of scientific articles, 131-148 (Svivt, Moscow, 2018)

5. A.N. Khizhnyak, Fundamentals of effective management: study guide (Infra-M, Moscow, 2019)

6. V.N. Kunitsyna, N.V. Kazarinova, V.M. Pogolsha, Interpersonal Communication. Textbook for universities (Piter, St. Petersburg, 2001)

7. N.P. Dedov, Problems of socio-psychological adaptation and professionalization of students in modern conditions of life, in Technologies of training and personality formation of a future specialist in the field of economics, taking into account the requirements of employers. Collective monograph, Ye.V. Kamneva, M.V. Polevaya, Zh.V. Korobanova (Eds.) (Prometheus, Moscow, 2018)

8. R. Ryberg, Advances in Life Course Research, 37, 1-14 (2018). https://doi.org/10.1016/j.alcr.2018.05.002

9. R. Burns, Self-concept development and education (Progress, Moscow, 1986)

10. O.B. Dutchina, The problem of the development of the self-concept of the student's personality (Publishing house of the Pacific State University, Khabarovsk, 2017)

11. O.A. Komissarova, Psychologist, 1, 16-24 (2019). https://doi.org/10.25136/24098701.2019.1.28941

12. L.N. Sobchik, Diagnostics of individual and typological properties and interpersonal relations. A practical guide (Rech, St. Petersburg, 2002)

13. T. Leary, I. Coffey, Interpersonal Diagnosis, in Theories of Personality Investigation, 73-96 (New York, 1969)

14. M.F. Hock, D.D. Deshler, J.B. Schumaker, Enhancing student motivation through the pursuit of possible selves, in Possible Selves: Theory, research, and application, 205221 (Nova Science Publishers Inc., New York, 2006)

15. K. Strauss, M.A. Griffin, S.K. Parker, Journal of Applied Psychology, 97(3), 580-598 (2012). https://doi.org/10.1037/a0026423 